\title{
Efeito da adição de enzimas na digestibilidade total aparente de dietas para leitões desmamados
}

\author{
Effect of enzymes addition on the total tract apparent \\ digestibility of piglet diets
}

\author{
Pryscilla Cency de Barros ${ }^{1}$; Vladimir de Oliveira ${ }^{2 *}$; \\ Clóvis Eliseu Gewehr ${ }^{3}$; Ricardo Vianna Nunes ${ }^{4}$
}

\begin{abstract}
Resumo
O estudo foi realizado com o objetivo de avaliar o efeito de amilase e protease, adicionadas de forma individual ou combinadas (amilase + protease) sobre a digestibilidade de nutrientes em dietas para leitões contendo milho duro. Dezesseis leitões machos castrados e desmamados aos 25 dias foram alojados individualmente em gaiolas de metabolismo. Os animais foram distribuídos em quatro dietas por meio de delineamento change over balanceado com dois períodos. As dietas foram isonutritivas e diferiram apenas na adição de enzimas: 1) sem enzimas; 2) 0,06\% de amilase; 3) 0,012\% de protease; e 4) $0,06 \%$ de amilase e $0,012 \%$ de protease. Não foram observados efeitos $(\mathrm{P}>0,05)$ da adição individual ou combinada de amilase e protease nos coeficientes de digestibilidade (CD) dos nutrientes avaliados. Os CD médios foram de 87,9, 88,2, 85,3, 77,7, 97,3 e 90,9\%, para a matéria seca, matéria orgânica, proteína bruta, matéria mineral, amido e energia bruta, respectivamente. Conclui-se que a adição de amilase e protease, individual ou combinada, não influencia a digestibilidade dos nutrientes de dietas para leitões contendo milho duro.
\end{abstract}

Palavras-chave: Aditivos, amilase, enzimas exógenas, milho, protease, suinocultura

\begin{abstract}
The experiment was realized to evaluate the effect of inclusion of amylase and protease alone or in combination on digestibility of piglets diets contend hard-endosperm corn. Sixteen castrated piglets weaned at 25 days were individually penned in metabolic crates and distributed in four diets using a balanced two period changeover design. The experimental diets were isonutritive and supplemented with $0.06 \%$ of amylase and $0.012 \%$ of protease alone or in combination. The results showed the amylase or protease alone or in combinations had no influence $(\mathrm{P}>0.05)$ on coefficients of digestibility in none of the two periods studied. The average of coefficients of digestibility were 87.9, 88.2, 85.3, 77.7, 97.3, and $90.9 \%$ to dry matter, organic matter, crude protein, ash, starch and gross energy, respectively. In conclusion, addition of amylase and protease alone or in combination have no influence on digestibility of piglets diets contend hard-endosperm corn.
\end{abstract}

Key words: Additives, amylase, corn, exogenous enzymes, pig production, protease

\footnotetext{
${ }^{1}$ Mestre em Zootecnia, Universidade Estadual do Oeste do Paraná, UNIOESTE, Marechal Cândido Rondon, PR. E-mail: pryscillabarros@gmail.com

2 Prof., Universidade Federal de Santa Maria, UFSM, Santa Maria, RS. E-mail: vladimir.oliveira@ufsm.br

3 Prof., Universidade Estadual de Santa Catarina, UDESC, Lages, SC. E-mail: a2ceg@cav.udesc.br

${ }^{4}$ Prof., UNIOESTE, Marechal Cândido Rondon, PR. E-mail: nunesrv@hotmail.com

* Autor para correspondência
} 


\section{Introdução}

A capacidade digestiva dos leitões é reduzida por ocasião do desmame e tem efeito direto sobre o desempenho dos animais na fase de creche (SCANDOLERA et al., 2005). É sabido, entretanto, que fatores como nutrição, ambiente e sanidade determinam a intensidade com que o desempenho será comprometido.

O uso de aditivos zootécnicos em dietas préiniciais e iniciais é comum e, tem como uma das finalidades, amenizar os desafios enfrentados pelos leitões nas primeiras semanas que sucedem o desmame, evitando-se assim, prejuízos ao desempenho (SILVA JUNIOR, 2009). As enzimas estão entre os aditivos de grande potencial para inclusão nas dietas de leitões, pois podem aumentar a capacidade de os animais assimilarem nutrientes vindo de fontes não-lácteas (CAINE et al., 1997).

A amilase atua na hidrólise do amido, principal fonte de energia presente na alimentação de leitões. Sua inclusão pode ser justificada pela baixa atividade da amilase pancreática no período imediato ao desmame (MAKKINK et al., 1994). Por outro lado, a protease pode incrementar a digestão de proteínas vegetais, como por exemplo, o farelo de soja. Isso porque a capacidade de digestão protéica fica comprometida devido à atrofia intestinal provocada pelo desmame (HEDEMANN; JENSEN, 2004).

Pode-se especular que uso combinado de amilase e protease poderia resultar em efeito sinérgico sobre a digestibilidade dos nutrientes de dietas para leitões. Uma das razões é que o milho cultivado no Brasil é de textura dura (CRUZ; PERREIRA FILHO; SILVA, 2012) e possui grânulos de amido envolvido por uma matriz protéica espessa e contínua (CHOCT et al., 2001). Foi demonstrado que a amilase tem um pequeno, mas significativo efeito na digestibilidade do amido de milhos com textura dura (PIOVESAN; OLIVEIRA; GEWEHR, 2011). Esse efeito da amilase poderia ser incrementado com a ação da protease que poderia auxiliar na digestão da matriz protéica que recobre os grânulos de amido.
Os resultados de estudos avaliando os efeitos da adição de amilase e protease nas dietas de leitões tem sido controversos (CAINE et al., 1997; MEDEL et al., 2002). De qualquer maneira, acredita-se que os efeitos da adição de enzimas declinam com a idade dos suínos, principalmente porque a capacidade de digestão aumenta com a idade (MAVROMICHALIS, 2006). Assim, o objetivo desse estudo foi avaliar a inclusão das enzimas amilase e protease, adicionadas de forma individual ou combinadas sobre a digestibilidade de dietas para leitões contendo milho duro e verificar se a idade do animal tem influência nas respostas obtidas.

\section{Material e Métodos}

O experimento foi realizado na Fazenda experimental Prof. Dr. Antônio Carlos do Santos Pessoa da Universidade Estadual do Oeste do Paraná, campus de Marechal Cândido Rondon.

Foram utilizados 16 leitões castrados desmamados aos 25 dias e com peso inicial de $8,05 \pm 1,2$ e $17,53 \pm 1,4 \mathrm{~kg}$ na primeira e segunda fase, respectivamente. Os animais permaneceram alojados individualmente em gaiolas de metabolismo projetadas para leitões na fase de creche. Cada uma das fases estudadas teve a duração de 12 dias, sendo sete destinados a adaptação às gaiolas e às rações experimentais e cinco dias para coleta total de fezes e urina. A ração fornecida era umedecida com água e administrada três vezes ao dia (06:00, 11:00 e 17:00 horas), permanecendo a disposição dos animais por 30 minutos, quando então recolhia-se as sobras e adicionava-se água no comedouro para que os animas tivessem acesso a vontade.

Os tratamentos experimentais consistiram de quatro rações isoenergéticas e isolisínicas (Tabela 1), formuladas para atender ou superar os níveis nutricionais recomendados pelo National Research Council - NRC (NRC, 1998). A única diferença entre as rações foi a adição de enzimas que ocorreu conforme o esquema a seguir: ração controle (ração basal sem enzima); ração basal com adição de 
amilase na proporção de $0,06 \%$; ração basal com adição de protease na proporção de $0,012 \%$; ração com adição de amilase e protease na proporção de $0,06 \%$ e $0,012 \%$, respectivamente.

A amilase utilizada era de origem fúngica, com atividade mínima de $4.000 \mathrm{SKB} \mathrm{g}^{-1}$ e nível de inclusão conforme recomendado pelo fabricante. $\mathrm{O}$ SKB (Sandstedt-Kneen-Blish) descreve o número de gramas de amido que é hidrolizado por um grama de amilase em uma hora sob condições ótima de $\mathrm{pH}$ e temperatura. A protease utilizada no estudo era de origem microbiana, termo resistente, com um mínimo de 250 unidades de protease por grama.

Tabela 1. Composição das dietas experimentais contendo ração basal (RB), RB + amilase, RB + protease, RB + amilase e protease.

\begin{tabular}{|c|c|c|c|c|}
\hline \multirow[b]{2}{*}{ Ingredientes } & \multicolumn{4}{|c|}{ Tratamento } \\
\hline & Controle & Amilase & Protease & Amilase + Protease \\
\hline Milho Duro & 56,60 & 56,54 & 56,58 & 56,52 \\
\hline Farelo de Soja & 25,00 & 25,00 & 25,00 & 25,00 \\
\hline Soro do Leite & 13,00 & 13,00 & 13,00 & 13,00 \\
\hline Açúcar & 2,00 & 2,00 & 2,00 & 2,00 \\
\hline Fosfato Bicálcico & 1,90 & 1,90 & 1,90 & 1,90 \\
\hline Calcário & 0,30 & 0,30 & 0,30 & 0,30 \\
\hline Sal & 0,30 & 0,30 & 0,30 & 0,30 \\
\hline $\mathrm{L}-$ Lisina & 0,25 & 0,25 & 0,25 & 0,25 \\
\hline DL_Metionina & 0,10 & 0,10 & 0,10 & 0,10 \\
\hline Vitamínico-mineral & 0,40 & 0,40 & 0,40 & 0,40 \\
\hline Óxido de Zinco & 0,15 & 0,15 & 0,15 & 0,15 \\
\hline Amilase $^{1}$ & - & 0,06 & - & 0,06 \\
\hline Protease $^{2}$ & - & - & 0,0125 & 0,0125 \\
\hline Item & \multicolumn{4}{|c|}{ Valores Calculados 3} \\
\hline Energia metabolizável $^{1}\left(\mathrm{Kcal} \mathrm{Kg}^{-1}\right)$ & 3325 & 3325 & 3325 & 3325 \\
\hline Proteína bruta $^{1}(\%)$ & 18,00 & 18,00 & 18,00 & 18,00 \\
\hline Amido (\%) & 36,70 & 36,70 & 36,70 & 36,70 \\
\hline Cálcio $^{1}(\%)$ & 0,825 & 0,825 & 0,825 & 0,825 \\
\hline Fósforo disponível $^{1}(\%)$ & 0,45 & 0,45 & 0,45 & 0,45 \\
\hline Lisina total $^{1}(\%)$ & 1,15 & 1,15 & 1,15 & 1,15 \\
\hline Metionina e cistina $^{1}(\%)$ & 0,70 & 0,70 & 0,70 & 0,70 \\
\hline Treonina $^{1}(\%)$ & 0,75 & 0,75 & 0,75 & 0,75 \\
\hline
\end{tabular}

${ }^{1}$ Enzima amilase incluída em substituição ao milho.

${ }^{2}$ Enzima protease incluída em substituição ao milho.

${ }^{3}$ Valores calculados segundo Rostagno et al. (2005).

Fonte: Elaboração dos autores.

Foi utilizada a metodologia de coleta total de fezes e urina e o oxido férrico $\left(\mathrm{Fe}_{2} \mathrm{O}_{3}\right)$ utilizado como marcador fecal. As fezes foram colhidas duas vezes ao dia, homogeneizadas e uma amostra de $20 \%$ foi armazenada. A urina foi colhida em recipiente com filtro contendo $10 \mathrm{~mL}$ de solução de $\mathrm{H}_{2} \mathrm{SO}_{4}(3,5 \mathrm{M})$ três vezes ao dia $(07: 00,12: 00$ e 18:00 horas), quantificada e uma amostra de $10 \%$ foi armazenada congelador. Os demais procedimentos metodológicos foram realizados de acordo com Oliveira et al. (2001).

$\mathrm{O}$ teor de amido dos ingredientes e fezes foi determinado pelo método de Lane-Eynon, o qual prevê que o teor de amido corresponde a 90\% do teor de açúcares totais, conforme descrito no 
Ministério da Agricultura e Abastecimento (1992). As análises químicas das rações, fezes e urina foram realizadas conforme metodologias descritas por Silva e Queiroz (2002).

A vitreosidade dos grãos de milho foi determinada pela dissecação manual dos grãos conforme procedimento descrito em Dombrink-Kurtzman e Bietz (1993). Foram selecionados aleatoriamente 30 grãos e divididos em 10 grupos, visualmente homogêneos em tamanhos e forma do grão (PRATT et al., 1995). Posteriormente, os grãos selecionados foram submersos em água destilada por três minutos e secos em papel toalha. Os grãos foram dissecados para remoção do pericarpo e embrião, restando o endosperma total que foi dividido em farináceo e vítreo. O peso do endosperma vítreo, expresso em proporção do endosperma total foi usado como medida de vitreosidade.

As variáveis analisadas nos oito tratamentos foram: coeficiente de digestibilidade da matéria seca (CDMS), coeficiente de digestibilidade da matéria orgânica (CDMO), coeficiente de digestibilidade da proteína bruta (CDPB), coeficiente de digestibilidade do amido (CDAMID), coeficiente de digestibilidade da energia bruta (CDEB), coeficiente de metabolizabilidade da energia bruta (CMEB), energia digestível (ED) e energia metabolizável (EM).

Foi utilizado o delineamento em changeover (GILL; MAGEE, 1976) com c observações (16 animais versus 2 períodos). Os dados obtidos foram submetidos a análise de variância usando o modelo $\mathrm{Y}_{\mathrm{ij}}=\mu+\alpha_{\mathrm{i}}+\beta_{\mathrm{j}}+\alpha_{\mathrm{i}} \beta_{\mathrm{j}}+\varepsilon_{\mathrm{ij}}$, onde $\alpha_{\mathrm{i}}+$ $\beta_{\mathrm{j}}+\alpha_{\mathrm{i}} \beta_{\mathrm{j}}$ representaram o efeito de dieta, período experimental e interação entre dieta e período experimental, respectivamente.

\section{Resultados e Discussão}

O milho utilizado no presente estudo apresentou $89 \%$ de matéria seca, $8,7 \%$ de proteína bruta e a proporção de endosperma vítreo foi de $73 \%$, o que o caracteriza como milho de endosperma duro (CANTARELLI et al., 2007).

$A$ adição de amilase não influenciou $(P>0,05)$ os coeficientes de digestibilidade (CD) avaliados (Tabela 2). Esses resultados divergem daqueles obtidos por Piovesan (2009), os quais demonstraram que a amilase aumenta a energia digestível e metabolizável de rações elaboradas com milho semi-duro. Por outro lado, em estudo conduzido por Mendel et al. (2002), também não ocorreu influência da amilase sobre a digestibilidade em rações de leitões.

Os CD dos nutrientes não foram influenciados pela presença de protease, contrariando resultados obtidos por Nery et al. (2000) os quais constataram incremento da digestibilidade da proteína em rações para leitões, devido a protease. Por outro lado, também são encontrados na literatura dados comprovando que a digestibilidade dos nutrientes e energia não sofre influência da protease. É o caso do experimento de Caine et al. (1997), utilizando protease exógena em dietas para leitões recém-desmamados, não observara efeito sobre a digestibilidade ileal aparente de nitrogênio e aminoácidos do farelo de soja.

A inclusão conjunta das enzimas amilase e protease não provocou o efeito sinérgico esperado nos CD dos nutrientes avaliados. Esperava-se influência dessas enzimas em razão de o milho duro possuir grânulos de amido recobertos por uma matriz protéica espessa e contínua (CHOCT et al., 2001), que dificulta sua digestão. A resistência que a parede celular vegetal exerce na ação das enzimas, talvez seja algo importante a ser considerado quando se projeta uma ação mais efetiva da amilase e da protease. 
Tabela 2. Coeficiente de digestibilidade (CD) da matéria seca (CDMS), matéria orgânica (CDMO), proteína bruta (CDPB), matéria mineral (CDMM), amido (CDAM) e energia bruta (CDEB) de ração com milho duro para leitões na creche com adição de amilase e protease, sozinhas ou em combinação.

\begin{tabular}{lccccccc}
\hline & \multicolumn{9}{c}{ Tratamento } & & & \\
\cline { 2 - 5 } Variáveis & Controle & Amilase & Protease & $\begin{array}{c}\text { Amilase }+ \\
\text { Protease }\end{array}$ & MÉDIA & EPM & Significância \\
\hline CDMS (\%) & 87,96 & 87,15 & 87,81 & 88,70 & 87,90 & 1,17 & NS \\
CDMO (\%) & 88,25 & 87,39 & 88,07 & 88,99 & 88,17 & 1,21 & NS \\
CDPB (\%) & 85,30 & 85,01 & 85,42 & 85,65 & 85,34 & 0,54 & NS \\
CDMM (\%) & 76,85 & 78,08 & 78,24 & 77,51 & 77,67 & 0,90 & NS \\
CDAM (\%) & 97,13 & 96,70 & 97,06 & 98,15 & 97,26 & 0,55 & NS \\
CDEB (\%) & 90,69 & 89,92 & 90,10 & 90,90 & 90,40 & 0,48 & NS \\
\hline
\end{tabular}

EPM: Erro padrão da média; NS: não significativo.

Fonte: Elaboração dos autores.

Os incrementos na digestibilidade da matéria orgânica, proteína bruta e fibra bruta obtidos com a inclusão de amilase, protease, celulase, $\beta$-glucanase e xilanase (GIANG et al., 2010) podem ser indicativos que enzimas com ação na parede celular são importantes para a efetividade da amilase e protease exógenas. De qualquer modo, a questão parece ser complexa, pois Olukosi, Sands e Adeola (2007) não constataram aumento no desempenho de leitões alimentados com rações suplementadas com combinação de xilanase, amilase e protease.
As razões que motivaram tais resultados não foram identificadas, mas fatores como a idade de desmame, característica das enzimas utilizadas e a composição e processamento da dieta podem estar envolvidos (McCLEARY, 2001).

Não ocorreram diferenças $(\mathrm{P}>0,05)$ entre os tratamentos nos valores de energia digestível (ED) e energia metabolizável (EM) determinados nos ensaios de digestibilidade (Tabela 3). Devido à ausência de efeitos nos coeficientes de digestibilidade dos nutrientes, esses resultados eram esperados.

Tabela 3. Energia digestível (ED) e energia metabolizável (EM) de ração contendo milho duro para leitões na creche com adição de amilase e protease, sozinhas ou em combinação.

\begin{tabular}{lccccccc}
\hline \multirow{2}{*}{ Variável } & Controle & Amilase & Protease & $\begin{array}{c}\text { Amilase }+ \\
\text { Protease }\end{array}$ & MÉDIA & EPM & Significância \\
\cline { 2 - 5 } & 3811 & 3748 & 3799 & 3835 & 3798 & 0,29 & NS \\
\hline ED (Kcal kg-1) & 3752 & 3705 & 3690 & 3743 & 3722 & 0,07 & NS \\
\hline EM (Kcal kg-1) & &
\end{tabular}

EPM: Erro padrão da média; NS: não significativo.

Fonte: Elaboração dos autores.

Embora não tenha sido um objetivo principal do estudo, observou-se que a digestibilidade dos nutrientes foi influenciada pelo período de coleta (Tabela 4). Os CD foram, em média, aproximadamente cinco pontos percentuais menores no período um em comparação ao período dois (as coletas de fezes iniciaram com 32 e 43 dias de vida, respectivamente). Essa diferença se aproxima da relatada por Giang et al. (2010) que encontraram diferenças médias de 3,6 pontos percentuais para o coeficiente de digestibilidade da matéria orgânica e proteína bruta ao comparar dados obtidos com leitões de 34 e 52 dias de idade, respectivamente. 
Tabela 4. Coeficiente de digestibilidade (CD) da matéria seca (CDMS), matéria orgânica (CDMO), proteína bruta (CDPB), matéria mineral (CDMM), amido (CDAM) e energia bruta (CDEB) de ração para leitões na creche em dois períodos.

\begin{tabular}{|c|c|c|c|c|}
\hline \multirow[b]{2}{*}{ Variável } & \multicolumn{2}{|c|}{ Período* } & \multirow[b]{2}{*}{ EPM } & \multirow[b]{2}{*}{ Significância } \\
\hline & 1 & 2 & & \\
\hline CDMS, \% & 85,61 & 89,99 & 0,77 & $<0,001$ \\
\hline CDMO, \% & 85,94 & 90,23 & 0,78 & $<0,001$ \\
\hline CDPB, $\%$ & 82,20 & 88,15 & 0,58 & $<0,001$ \\
\hline CDMM, \% & 73,34 & 81,02 & 0,98 & $<0,001$ \\
\hline CDEB, $\%$ & 88,69 & 92,03 & 0,49 & $<0,001$ \\
\hline
\end{tabular}

*Média de 34 e 45 dias de idade nos períodos 1 e 2 , respectivamente.

Fonte: Elaboração dos autores.

Em outros estudos foi demonstrado que a digestibilidade ileal aparente da proteína sofre influência da idade em leitões recém desmamados, sendo os valores encontrados nas duas primeiras semanas após o desmame inferiores aos obtidos nas duas semanas seguintes (CAINE et al., 1997; GUGGENBUHL; WACHÉ; WILSON, 2012). Apesar de não ser possível comparar esses resultados com os obtidos no nosso estudo, pois determinamos a digestibilidade total, essas informações também confirmam o efeito da idade sobre a capacidade digestiva dos suínos.

O declínio da capacidade digestiva dos suínos, durante as primeiras semanas que sucedem o desmame, é descrito na literatura científica (PLUSKE; WILLIAMS; AHERNE, 1996; VENTESPREEUWENBERG et al., 2003; MONTAGNE et al., 2007). O principal motivo parece ser a necessidade de adaptação dos leitões ao consumo de uma dieta com características químicas e físicas diferentes do leite materno. O período de tempo necessário para que a adaptação ocorra é dependente de inúmeros fatores, embora a maioria dos resultados científicos revelam que entre 10 e 14 dias são suficientes. Diante disso, as diferenças entre os coeficientes de digestibilidade e valores energéticos observados no presente estudo possivelmente sejam um reflexo da idade do animal e sua necessidade de adaptação pós-desmama.

Por outro lado, é importante destacar que o efeito da idade na digestibilidade pode depender da composição química da dieta. Dietas de menor complexidade, contendo quantias elevadas de milho e farelo de soja, podem ser mais influenciadas pelo efeito da idade dos suínos em comparação com dietas possuindo maior proporção de ingredientes altamente digestíveis (TRINDADE NETO et al., 2010). Não foram encontrados experimentos que pudessem confirmar a veracidade dessas suposições, de forma a realização de estudos para esclarecer essa questão seria importante.

\section{Conclusão}

A adição de amilase e protease individual ou combinada em rações para leitões na fase de creche não alterou os coeficientes de digestibilidade das dietas contendo milho duro.

\section{Agradecimentos}

Os autores agradecem a CAPES pela bolsa de estudos concedida a primeira autora.

\section{Aprovação no Comitê de Ética}

Este trabalho foi aprovado na comissão de ética no uso de animais Comitê de Ética na Experimentação Animal e Aulas Práticas - CEEAAP da Unioeste sob parecer número 1909/2009, considerando seus aspectos éticos e metodológicos. 


\section{Referências}

CAINE, W. R.; SAUER, W. C.; TAMMINGA, S.; VERSTEGEN, M. W.; SCHULZE, H. Apparent ileal digestibilities of amino acids in newly weaned pigs fed diets with protease-treated soybean meal. Journal of Animal Science, Champaign, v. 75, n. 11, p. 2962-2969, 1997.

CANTARELLI, V. S.; FIALHO, E. T. F.; SOUSA, R. V.; RILKE, T. F.; LIMA, J. A. F. Composição química, vitreosidade e digestibilidade de diferentes híbridos de milho para suínos. Ciência e Agrotecnologia, Lavras, v. 31, n. 3, p. 860-864, 2007.

CHOCT, M.; BIRD, S. H.; LITTLEFIELD, P.; BALOGUN, R.; ROWE, J. B. Microstructure of grains as an indicator of nutritive value. In: CORBETT, J. L.; CHOCT, M.; HUGHES, R. J.; PEREZ-MALONADO, R.; Van BARNEVELD, R. J. Recent Advances in Animal Nutrition in Australia, New England, v. 13, p. 223-228, 2001.

CRUZ, C. C.; PERREIRA FILHO, I. A.; SILVA, G. H. Milho: cultivares para 2011/2012. Sete Lagoas: Embrapa Milho e Sorgo, 2012. Disponível em: <http://www. cnpms.embrapa.br/milho/cultivares/index.php/>. Acesso em: 10 jun. 2013.

DOMBRINK-KURTZMAN, M. A.; BIETZ, J. A. Zein composition in hard and soft endosperm of maize. Cereal Chemistry, St. Paul, v. 70, n. 1, p. 105-108, 1993.

GIANG, H. H.; VIET, T. Q.; LINDBERG, J. E.; OGLE, B. Effects of microbial enzymes and a complex of lactic acid bacteria and Saccharomyces boulardii on growth performance and total tract digestibility in weaned pigs. Livestock Research for Rural Development, Cali, v. 22, n. 10, p. 1-4, 2010.

GILL, J. L.; MAGEE, W. T. Balanced two-period changeover designs for several treatments. Journal of Animal Science, Champagne, v. 42, n. 3, p. 775-777, 1976.

GUGGENBUHL, P.; WACHÉ, Y.; WILSON, J. W. Effects of dietary supplementation with a protease on the apparent ileal digestibility of the weaned piglet. Journal of Animal Science, Champaign, v. 90, p. 152-154, 2012. Supplement 4.

HEDEMANN, M. S.; JENSEN, B. B. Variations in enzyme activity in stomach and pancreatic tissue and digesta in piglets around weaning. Archives of Animal Nutrition, Berlin, v. 58, n. 1, p. 47-59, 2004.

MAKKINK, C. A.; NEGULESCUS'S, G. P.; GUIXIN, Q.; VERSTEGEN, M. W. A. Effect of dietary protein source on feed intake, growth, pancreatic enzyme activities and jejunal morphology in newly-weaned piglets. British Journal of Nutrition, Cambridge, v. 72, n. 3, p. 353-368, 1994.

MAVROMICHALIS, I. Applied nutrition for young pigs. London: CAB International, 2006. v. 1, 297 p.

McCLEARY, B. V. Analysis of feed enzymes. In: BEDFORD, M. R.; PARTRIDGE, G. G. (Ed.). Enzymes in farm animals. Oxford: CAB Publishing, 2001. p. 85108.

MEDEL, P.; BAUCELLS, F.; GRACIA, M. I.; DE BLAS, C.; MATEOS, G. G. Processing of barley and enzyme supplementation in diets for young pigs. Animal Feed Science and Technology, Amsterdam, v. 95, n. 3-4, p. 113-122, 2002.

MINISTÉRIO DA AGRICULTURA E ABASTECIMENTO. Compêndio brasileiro de alimentação animal. In: SINDIRAÇÕES. (Ed.). Matériaprima. Brasília: ANFAR: CBNA, SDR/MA, 1992. n. 34, p. 99-102.

MONTAGNE, L.; BOURDRY, G.; FAVIER, C.; Le HUEROU-LURON, I.; LALLES, J. P.; SEVE, B. Main intestinal markers associated with the changes in gut architecture and function in piglets after weaning. British Journal Nutrition, Cambridge, v. 97, n. 1, p. 45-57, 2007.

NATIONAL RESEARCH COUNCIL - NRC. Nutrient requirements of swine. 10. ed. Washington: National Academy Press, 1998. 189 p.

NERY, V. L. H.; LIMA, J. A. F.; MELO, R. C. A.; FIALHO, E. T. Adição de enzimas exógenas para leitões dos 10 aos $30 \mathrm{~kg}$ de peso. Revista Brasileira de Zootecnia, Brasília, v. 29, n. 3, p. 794-802, 2000.

OLIVEIRA, V.; FIALHO, E. T.; LIMA, J. A. F.; OLIVEIRA, A. I. G.; FREITAS, R. T. F. Substituição do milho por casca de café em rações isoenergéticas para suínos em crescimento e terminação. Ciência e Agrotecnologia, Lavras, v. 25, n. 2, p. 424-436, 2001.

OLUKOSI, O. A.; SANDS, J. S.; ADEOLA, O. Supplementation of carbohydrases or phytase individually or in combination to diets for weanling and growing-finishing pigs. Journal of Animal Science, Champaign, v. 85, n. 7, p. 1702-1711, 2007.

PIOVESAN, V. Milhos com diferentes texturas de endosperma e adição de alfa amilase na ração de leitões. 2009. Dissertação (Mestrado em Zootecnia) Universidade Estadual do Oeste do Paraná, Marechal Cândido Rondon. 
PIOVESAN, V.; OLIVEIRA, V.; GEWEHR, C. E. Milhos com diferentes texturas de endosperma e adição de alfa-amilase na dieta de leitões. Ciência Rural, Santa Maria, v. 41, n. 11, p. 2014-2019, 2011.

PLUSKE, J.; WILLIAMS, I.; AHERNE, F. Maintenance of villus height and crypt depth in piglets by providing continuous nutrition after weaning. Animal Science, Penicuikv, v. 62, n. 1, p. 131-143, 1996.

PRATT, R. C. PAULIS, J. W.; MILLER, K.; NELSEN, T.; BIETZ, J. A. Association of zein classes with maize kernel hardness. Cereal Chemistry, St. Paul, v. 72, n. 2, p. 162-167, 1995.

ROSTAGNO, H. S.; ALBINO, L. F. T.; DONZELE, J. L.; GOMES, P. C.; OLIVEIRA, R. F.; LOPES, D. C.; FERREIRA, A. S.; BARRETO, S. L. T. Tabelas brasileiras para aves e suínos. Composição de alimentos e exigências nutricionais. Viçosa: UFV, Departamento de Zootecnia, 2005. 186 p.

SCANDOLERA, A. J.; THOMAZ, M. C.; KRONKA, R. N.; FRAGA, A. L.; BUDIÑO, F. E. L.; HUAYNATE, R. A. R.; RUIZ, U. S.; CRISTANI, J. Efeitos de fontes protéicas na dieta sobre a morfologia intestinal e o desenvolvimento pancreático de leitões recémdesmamados. Revista Brasileira de Zootecnia, Brasília, v. 34 , n. 6, p. 2355-2368, 2005. Suplemento.
SILVA JUNIOR, A. Interações químico-fisiolóficas entre acidificantes, probióticos, enzimas e lisofosfolipídios na digestão de leitões. Revista Brasileira de Zootecnia, Brasília, v. 38, p. 238-245, 2009. Suplemento Especial.

SILVA, D. J.; QUEIROZ, A. C. Análise de alimentos: métodos químicos e biológicos. 3. ed. Viçosa, MG: Universidade Federal de Viçosa, 2002. 235 p.

TRINDADE NETO, M. A.; BRUNO, D. G.; BERTO, D. A.; UNDI, M.; SCHAMMASS, E. A. Apparent digestibility of diets with different concentration of lysine and energy in piglets with different body weights and post-weaning age. Revista Brasileira de Zootecnia, Brasília, v. 39, n. 8, p. 1784-1790, 2010.

VENTE-SPREEUWENBERG, M. A. M.; VERDONK, J. M. A. J.; VERSTEGEN, M. W. A.; BEYNEN, A. C. Villus height and gut development in weaned piglets receiving diets containing either glucose, lactose or starch. British Journal of Nutrition, Cambridge, v. 90, n. 5, p. 907-913, 2003. 